\title{
PD with a Passport: Reflections on Professional Development through Volunteer Work in Emerging Central American Libraries
}

\author{
Cate Carlyle \\ Coordinator \\ Curriculum Resource Centre \\ Mount Saint Vincent University \\ cate.carlyle@msvu.ca
}

\begin{abstract}
For many librarians, professional development involves system-wide training days, webinars, massive open online courses (MOOCs), annual association conferences, and workshops. While such activities are necessary for learning new skills and technologies, some professionals crave a different kind of professional development. Volunteering as an international librarian can be a very rewarding and fulfilling challenge, an incredible personal and professional learning experience, but one that should not be entered into lightly. Based on the author's experience volunteering in Guatemala with Librarians Without Borders, this article describes some of the issues involved when volunteering in Central America. Practical advice for selecting a service trip, costs, health and medical requirements, personal and professional issues, and work scope are some of the areas discussed.
\end{abstract}

\section{Keywords}

professional development; international librarianship; career development; continuing education; volunteerism; Librarians Without Borders

\section{Introduction}

Professional development (PD) opportunities for librarians tend to fall under the categories of in-service training, webinars, online courses, and annual conferences. While such PD is necessary and relevant, it can become dull and repetitive. In early 2014 I found myself searching for a unique PD opportunity-something meaningful and creative to recharge my professional batteries. While browsing the Librarians Without Borders (LWB) website, I noticed a structured service trip to two emerging libraries in Guatemala. Excited by the notion of travel, being involved in the evolution of libraries in very disadvantaged areas of Central America, and testing myself both personally and professionally, I applied. What started out as a very scary "what have I done?" moment, became a very meaningful life experience. But volunteering internationally is not for 
everyone, and the logistics and preparation involved can be daunting. Starting out with a structured trip, as I did, is recommended for both your physical and mental wellbeing. The issues of trip selection, cost, health and medical concerns, personal and professional issues, and work scope should all be investigated before embarking on such a journey. Preparation and knowledge are key to a positive international venture.

\section{Trip Selection}

There are not many structured service trips for librarians (see Resource section). The LWB trip to Guatemala included librarians and MLIS students from Spain, Ireland, Canada, and the United States, most of whom found the trip through simple Google searches. The LWB trip required an application stating your professional experience, interests, fitness level, travel experience, and applicable skills. Twelve volunteers were ultimately selected from all applicants. For many, a deciding factor in applying was the fact that the trip included escorted day trips on the weekends: a volcanic hot spring spa, guided tours of historical attractions, a mountain hike, and a soccer game. In addition, the short two-week trip duration was attractive for those first timers unsure what to expect.

It is important to research any trip you are considering. Some tips for researching your trip beforehand:

- Look at blog postings and Flickr or Instagram pictures from previous groups.

- Reach out to your library association, and speak to any members who have participated or know someone who has been on previous trips with the provider you are interested in. Check what will be included and what won't, and tailor the type of experience you are looking for to the offered trips.

- Visit the Canadian government's travel advisory page to learn about any safety issues in the region as well as visa requirements. (http://travel.gc.ca/travelling/advisories)

Ideally you need to find the right balance of length of trip, cost, and locale. While my knowledge of Guatemala was limited prior to the trip, I was aware that it is a dangerous country, particularly for women. That being said, the short duration, reasonable cost, pre-trip training sessions, and correspondence with past participants reassured me that I was choosing the correct venue for my volunteer experience. In short, contact the trip provider and ask lots of questions.

\section{Costs}

Even though you are "volunteering" as a professional, you will most likely still have to pay a fee for your service trip. Such a fee can vary, and you will have to decide what you are comfortable with. While my $\$ 1000$ fee was not subsidized, some employers or unions will pay this fee (and other costs incurred) from their PD budgets. It is worth asking your institution what, if anything, it might cover. 
Additional costs may include your return flight, medications, supplies, any donations you may make, room and board, etc. Room and board was included in the fee for my LWB trip, as well as transportation while in Guatemala, recreational side trips, and a small donation to two libraries. I was responsible for my flights, extra snacks or supplies I wished to bring, spending money, and any book or supply donations I chose to make once on the ground.

You may also be responsible for any necessary medical costs, including vaccinations and medications. Since only some of the vaccinations I elected to receive were covered by my employee benefits, this proved costly, at approximately $\$ 400$. Mosquito nets for sleeping were not provided or required but are something to consider bringing to Central America. Nets can be purchased online for $\$ 5$ to $\$ 40$ each.

While a visa may not be required for travel to some volunteer trip destinations, you may incur costs to acquire or update your passport. Travel insurance will also be an expense if you do not already have this through your benefits. In addition, you will want to take into account whether or not you will be paid by your employer while away, whether you have to take holiday time to cover the trip, or whether the trip will be considered leave for PD or unpaid leave.

You may not have to cover all volunteer trip expenses yourself. There are many crowdfunding platforms available, including Kickstarter and Indiegogo. To pay for some of my costs, I chose to fundraise online via Facebook, using fundrazr.com, and this proved very successful. Fundrazr does take a small percentage from your funds but is very convenient, and donations can be made and withdrawn using Paypal.

Unfortunately, LWB is not a registered charity and the lack of a tax receipt for donations did inhibit my fundraising.

As well as your employer or union, it is a good idea to check for available funds from relevant library associations. Make such requests well in advance of the trip. I received a grant towards my trip costs from my regional library association in return for the promise of an article about my experience on my return.

\section{Health and Medical}

One component of the LWB application was a fitness evaluation. Applicants were asked to rate their fitness level and overall health, and to describe their regular fitness routine. It became apparent while on the trip that this was necessary because of the amount of walking involved, as well as some of the weekend side trips (hiking, swimming, soccer). Some participants did choose to opt out of these physical activities once on the trip. No doctors' notes or references were required; the onus was on the applicant to be honest in the self-evaluation.

The Guatemalan diet is mainly vegetarian, with a wealth of tortillas, rice and beans, and a lack of protein, dairy, sugar, and leafy green vegetables. You will lose weight while volunteering in Central America, as you will be quite active and will not be ingesting the 
usual North American foods. This can wreak havoc on your digestive system during the trip and for a short period upon returning to your normal diet. If you have strict dietary restrictions, you will want to discuss these with the trip provider and also bring food supplements with you. The meal providers on our trip tried to accommodate the lone vegan participant, but this was not always possible, and the participant had to be flexible. We were assured that our meal providers followed North American standards for cleanliness. However, volunteers were discouraged from eating at food stalls or purchasing food from local vendors. The "boil it, cook it, peel it, or forget it" rule was encouraged and followed during the service trip.

During our pre-trip, online training sessions, the need for vaccinations and medications was discussed. Each participant was encouraged (but not required) to visit a travel clinic at least six weeks prior to departure and begin the round of vaccinations suggested for travel to Guatemala. I chose to receive all vaccinations recommended by my travel doctor (for malaria, typhoid, tetanus, and hepatitis), as well as to take medications for diarrhea and stomach viruses with me. While I did not suffer any illness or stomach issues, many in our group did succumb for a few days. Although no one required hospitalization, it is important to ask what the protocol is for such emergencies and whether your service provider is equipped to handle such a situation. Ask questions! If you are unsure that the trip provider takes your health seriously, then perhaps reconsider.

\section{Personal Issues}

Traveling and rooming with a small group of professionals and students in a foreign country can be stressful and is not for everyone. Some of the accommodations in Guatemala were hostels offering dorm-type environments with bunk beds, eight people to a room, and one bathroom. Personalities, opinions, habits, sleeping rituals, homesickness, illness, noise levels, room temperature, and scents may suddenly become very important when we are far away from home in a foreign environment. On my trip this was too much for one participant, and accommodations were made to allow for a single room, but that is not always possible. If something as simple as a lack of hot water in the shower (or no shower) would prove too stressful, then a service trip might not be for you.

After-work activities can also prove difficult as some participants may be night owls, wanting to socialize or experience local night life. Flexibility and the desire to experience all aspects of a group trip are important when considering volunteering internationally. Not everyone will get along. Participation will require personal adjustments and the ability to function within a team.

Communicating with your loved ones at home may also be problematic. In Guatemala we were able to visit an internet café on some days to communicate with family, but there were many days when communication was impossible. While the trip leader carried a cell phone, and our families were given that number, it was for emergencies only. 


\section{Professional Issues}

In terms of communicating professionally with library personnel in Guatemala, we were lucky that at least one-third of the members of our group spoke Spanish. While the staff at the emerging library in remote Chajul spoke the Mayan dialect Ixil, our Spanish speakers were still able to communicate with them. If you do not speak the local language of your service trip destination, ask whether there will be interpreters or English speakers on the ground.

As we were working in very traditional communities with entrenched customs, dress code was an issue. Although the region was quite hot and humid, women were expected to be covered and wear either pants, or skirts and dresses of modest length. The men wore pants and lightweight shirts and tees. Dress code was specified prior to the trip, but there were incidents when volunteers were asked to change their outfits as the skirt length was too short.

Having a mix of LIS students and older professionals (public, academic, and special librarians) also proved challenging for some participants due to differing perspectives and experience levels. If you are going to live and work with a diverse group, it is best to arrive with an open mind and a team mentality. It is important to see the big picture and embrace the fact that those volunteering with you are also there for the greater good and have similar goals. I found that the participants who got the most out of the volunteer trip were those whose mindset was such that they were open to learning about new ideas and tools from their colleagues. They not only gave of their own skills but benefitted from the group's collective knowledge and experience.

\section{Work Scope}

My LWB trip included the opportunity to select our preferred areas of work. Participants could catalogue materials, create and deliver programming, and/or manage the social media aspects of the trip. I chose cataloguing and participated in pre-departure online training sessions with my colleagues, including mock cataloguing tasks which were evaluated by the trip leaders. Such pre-trip training was invaluable in preparing us to "hit the ground running" as well as lessening our apprehensions about expectations. Once in Guatemala, our cataloguing work was completed each weekday between 9:00 a.m. and 4:00 p.m. It is important to ask early on what is expected in terms of the scope of the work involved, goals for completion by the end of the trip, and necessary expertise. A volunteer trip might also be a good time to expand your horizons by taking on a task for which you may not be an expert, and benefitting from some experiential learning. Moving out of your comfort zone and usual prescribed tasks to learn something new, or revisit a skill you no longer use, allows for the growth and challenge which comes from quality professional development.

Find out whether or not you will be required to report on your experience and whether your photo and reflections will be used to promote the organizations involved. Each 
participant in Guatemala was required to contribute a blog post, as well as a video introduction, and to authorize the use of their photo. Is your employer comfortable with you representing your institution while away? Are you comfortable having your likeness linked to the group organizing the trip and its stakeholders? These are questions to ask prior to committing.

One of the most important things to be aware of when volunteering in Central America is that nothing happens fast. Do not be dismayed if you are only planting initial seeds for a new library or information service that will grow and develop under the nurturance of subsequent volunteers. For example, the school library in Xela where I volunteered is only just beginning to lend books to their students on a limited basis after a few years of service trips, volunteer work, cataloguing, and training. The focus has been on cataloguing the collection and teaching the ideas of lending, responsibility, and care of the items, so that when lending does begin the books are returned in good condition. Not all cultures have been exposed to the idea of borrowing an item, caring for it, and returning it on schedule. A main concern for the library in the remote area of Chajul was that children were stockpiling the safety pins that the library provided to attach their library cards/entrance passes to their shirts. Families were keeping the pins as they were valuable in their home environments. Such simple dilemmas, which may not be an issue in North America, need to be resolved before the actual lending of the more costly collection items can even be considered.

Finally, some members of my cataloguing team were surprised to find that previous volunteers had catalogued items a bit differently, and there was concern that our work might not be maintained in the future by volunteers visiting from other organizations. Find out what procedures are in place or need to be instituted to ensure that your efforts are worthwhile and will be preserved after you leave. Standardize procedures that are clear and easy to follow; train the local staff and volunteers, and leave written instructions, samples, or how to videos. If you are comfortable doing so, leave your contact information for any questions that may arise after your departure. If your work cannot be maintained and built upon, then your efforts will have been in vain.

\section{The Payoff}

In my experience, the personal and professional rewards from volunteering internationally cannot be matched. I gained professional knowledge from the group of information professionals and students on my team, as well as from the library staff and NGO workers on the ground in Guatemala, and the LWB executives in Canada. I am a huge proponent of experiential learning, and the growth I achieved in two weeks could not have been matched in a decade of in-service training, webinars, and slide presentations. A particularly vivid memory is that of cataloguing resources and working through Dewey classification and subject heading issues in a small, humid, unlit storage room with six other librarians from Canada, the US, and Europe. We worked through how best to catalogue the donated materials to suit the information needs of the young Guatemalan children who would eventually borrow them. We were forced to manage multiple priorities: blogging entries for the LWB site, cataloguing and programming 
delivery, and photo documentation-in subject areas, age groups, and locales with which we were unfamiliar-and still sit down to dinner each night as friends and roommates.

Volunteering in unfamiliar conditions with a diverse group of individuals develops such critical leadership skills as self-motivation and self-direction (Farrell). Utilizing skills you may no longer use regularly in your day job or learning new skills from the team, and being forced to quickly become part of a team with which you will not only work but also live, are unique and powerful life-changing experiences. Leaving one's comfort zone and living and working closely with new colleagues creates a focus on group dynamics and diplomacy—both important leadership skills (Farrell). Navigating intense pedagogical discussions, compromising, and knowing when to lead and when to follow are critical to professional leadership. In addition, working with other volunteers will increase your professional network. Staying in touch after the service trip is important, and platforms such as Facebook and Linkedln are useful for networking.

Seeing the impact of our work on the local library users and the gratitude from the Guatemalan staff and children reignited a passion for the power of libraries and freedom of information that had been dwindling in my library advocacy work. In an era when users complain of technological glitches, bandwidth, and the type of coffee served in their library café, the small moments when volunteering internationally are priceless. I have a memory of a tiny Guatemalan child sitting beside me while I read to her in English from a book about colours. Neither of us spoke the other's language, but we communicated somehow and taught each other new words. She was entranced by the colour of my skin and my odd North American clothing, eager to teach me the Spanish words for the colours of each. It is my hope that she left that day with an interest in books, reading, and the unknown, and that she would be returning to the library regularly even after the strange group of visitors had left.

\section{Resources}

The following resources may be of interest to those researching international volunteer opportunities. The organizations listed focus primarily on structured service trips with varying levels of support before and during the trip.

\section{Librarians Without Borders}

http://lwb-online.org

For both LIS professionals and MLIS students.

Non-profit Canadian organization governed by a volunteer executive team and MLIS student chapters. Membership is free, and service trip opportunities usually occur annually with trip details posted early each year.

Volunteer opportunities can be found in the "Programs" section. 
The Traveling Librarian

http://sarahpgibson.wordpress.com/

For both LIS professionals and students.

Librarian Sarah P Gibson's blog provides links to both international volunteer and employment postings from various associations.

People to People Citizen Ambassador Programs

https://citizens.peopletopeople.com/OurPrograms/CAP/Pages/default.aspx

For LIS professionals.

American global educational travel provider started in the 1950s by President Eisenhower. LIS service trips can be found under "Education" and "Library and information services". Can be costly.

American Library Association (ALA) International Opportunities http://www.ala.org/irrt/irrtcommittees/irrtintlexc/opportunitiesfrontpage

For both LIS professionals and students.

Listing of resources related to exchanges, fellowships, grants, sister libraries, volunteer and employment opportunities.

Global Library Volunteer Network

http://libraryprojects.org/

For both LIS professionals and students.

Canadian group recently created by former Librarians Without Borders members. GLVN is currently constructing a database of international volunteer opportunities. Stay tuned.

\section{Works Cited}

Farrell, Maggie. "Leadership Reflections: Leadership Development through Service." Journal of Library Administration 54.4 (2014): 308-17. Web. 10 Sept. 2014. < doi:10.1080/01930826.2014.924317>. 